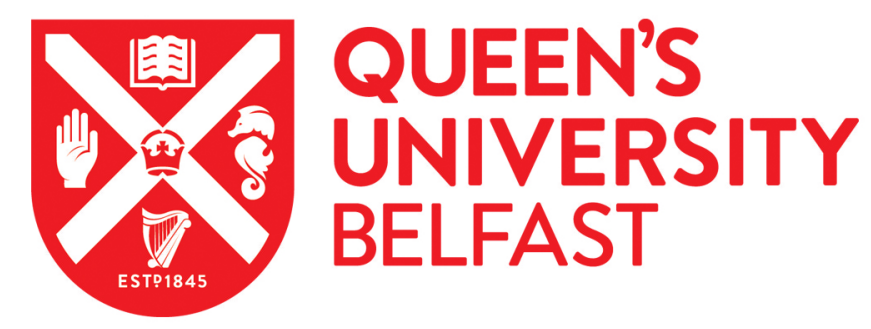

\title{
The Voice as Transcursive Inscriber: The Relation of Body and Instrument Understood through the Workings of a Machine
}

Schroeder, F. (2006). The Voice as Transcursive Inscriber: The Relation of Body and Instrument Understood through the Workings of a Machine. Contemporary Music Review, 25(1-2)(1-2), 131-138.

https://doi.org/10.1080/07494460600647550

\section{Published in:}

Contemporary Music Review

Queen's University Belfast - Research Portal:

Link to publication record in Queen's University Belfast Research Portal

\section{General rights}

Copyright for the publications made accessible via the Queen's University Belfast Research Portal is retained by the author(s) and / or other copyright owners and it is a condition of accessing these publications that users recognise and abide by the legal requirements associated with these rights.

Take down policy

The Research Portal is Queen's institutional repository that provides access to Queen's research output. Every effort has been made to ensure that content in the Research Portal does not infringe any person's rights, or applicable UK laws. If you discover content in the Research Portal that you believe breaches copyright or violates any law, please contact openaccess@qub.ac.uk. 


\title{
The Voice as Transcursive Inscriber: The Relation of Body and Instrument Understood through the Workings of a Machine
}

\author{
Franziska Schroeder
}

This article examines the relationship of the body with a musical instrument; specifically it looks at the vital threshold conditions that occur during the interplay of voice and instrument. By examining the work 'IKAS' (1982) for solo saxophone by German composer Hans-Joachim Hespos, the unusual timbral relationships created between vocal and instrumental sounds are exposed. I argue that this particular work highlights the performer/instrument relation as one marked by Gilles Deleuze's notion of the workings of a machine and a machine's relation to a 'flow', in particular a machine's function with view to the break in the flow. By turning towards Deleuze's concept of the machine, this article offers a slightly different vocabulary for music analysis, one that more easily encompasses certain works of the twentieth century, specifically those that are more timbre- than pitch-based.

Keywords: Performer; Instrument; Voice; Deleuze, Gilles; Machine; Break-downs

\section{Instrumental Prosthesis}

When thinking of ways in which an instrumentalist engages with his or her instrument, the notion of extension seems to be of vital significance. One thinks of the performer, the voice and the instrument as existing as a dynamic whole, in which the instrument is understood as an extension of the body. Let me elaborate on this: when a wind player produces a certain note, he or she thinks of the air that has been breathed in as building or emanating from 'below': the diaphragm is the 'starting place', which pushes the air upwards into the lungs. The air then gets pushed from the lungs through the vocal tract (this includes various parts, such as the larynx, the uvula, the soft and hard palate, as well as throat, tongue, teeth and lips) into the mouthpiece of the instrument. For this passage from vocal cavity to instrument to be 
successful in the production of the desired sound, the vocal cavity has to be shaped to match the specifics of the instrument (the reed on the mouthpiece, the size of the instrument's neck and bell, for example). Once this has taken place the sound can become voiced, so to speak. In that way, when sounding a note on an instrument the performer thinks of the voice, or the shaping of the sound, as preceding the instrument. And it is an essential concept to grasp for playing an instrument that produces sounds with the aid of the human breath. Indeed, the beginner instrumentalist is constantly reminded to 'open and relax his or her throat', in order for air to freely travel from the body into the instrument; a continuous flow of air from the body that becomes transferred to the instrument is wished for.

It is worth noting that this idea of voicing oneself through the instrument also establishes something particular about relations of facing and frontality. When giving voice, I produce sounds, and when speaking I also produce myself. Speaking, then, establishes me as a self-producing being; the voice is my way of going out from myself, so Connor suggests $(2000$, p. 4). 'When I speak, my voice shows me up as a being with a perspective, for whom orientation has significance, who has an unprotected rear, who has two sides, [and] if my voice is out in front of me, this makes me feel that I am somewhere behind it' (Connor, 2000, p. 5). This implies that the performer exposes his or her voice, as voiced by the instrument, as coming from inside his or her body and going into an exterior space, one that extends beyond the body. The performer's sounds establish him or her 'as an inside capable of recognising and being recognised by an outside' (Connor, 2000, p. 6).

Seen in this light, the voice becomes an 'extended reach', similarly seen in the newborn baby whose voice is a way of reaching the carer's attention. The infant reaches out by means of its cry (Connor, 2005). ${ }^{1}$ Thus, one can argue that the instrument is an extension, the object with which one makes sounds. Naomi Cumming (2000) sees the instrument in this way: as the performer's voice. The body becomes transferred onto the instrument, with which it turns towards the world for its existence, exposing a phenomenological reading of the performer/instrument relation. This aligns with Merleau-Ponty's view of the blind man's stick where the stick's pressure on the man's hand is no longer given; 'the stick is no longer an object perceived by the blind man, but an instrument with which he perceives. It is a bodily auxiliary, an extension of the bodily synthesis' (Merleau-Ponty, 1999, p. 152).

The idea of transferring our abilities to some kind of external support, of transferring a skill onto body capabilities, has been referred to as 'exteriorization' by the French anthropologist André Leroi-Gourhan (1993, p. 246). This in turn recalls ideas of body 'extension' and 'prosthesis'. Already inherent in the Greek origin of the word 'prosthesis', the idea of extending, adding and enhancing is exposed: 'prostithenai' derives from 'prostithenai': 'pros' = 'to' and 'tithenai' = 'to put, to place', meaning to 'add to' ${ }^{2}$. Thus, the instrument is added on to; it has become the performer's prosthesis. The idea of prosthesis has been widely incorporated into the arts, not only by instrumentalists, ${ }^{3}$ but also by various other performing artists. Some of the possibly most widely known artworks that deal with extension are the works by 
Stelarc. One of Stelarc's earlier body-extending projects, 'The Third Hand' (19761981), in which an artificial hand is attached to one of Stelarc's arms, emphasizes the notion of addition. ${ }^{4}$ Stelarc's work 'Hexapod', also a work that deals with the idea of extension, is a work/installation/performance project in which Stelarc's limbs become extended into a huge insect-like mechanical structure. Stelarc, who is at the center of the electrical and pneumatic mechanical structure, controls the movements through his own body weight. ${ }^{5}$

\section{The Workings of a Machine}

I now want to propose a reappraisal of this centrifugal way of thinking of the instrument as an add-on, and reconsider this idea of instrumental sounds moving from the body into the instrumental prosthesis. ${ }^{6}$ In order to do so, I will examine a work for solo saxophone by Hans-Joachim Hespos entitled 'IKAS' (1982). ${ }^{7}$ I will argue that in a work like this there is a great need for reconsidering and reconceptualizing ways in which the performer's voice is being used in the production of instrumental sounds. It will become clear that the voice ceases to be the predecessor of the instrumental sound; thus, notions of extension will have to become entirely rethought. I want to think of the performer-voice-instrument 'continuum' in terms of a specific technology, what one could call a 'Deleuze-ian machine'. I propose a Deleuze-ian approach to the workings of a machine in order to understand the intricate relationship of voice, performer and instrument in a different light.

Deleuze and Guattari suggest that machines are real and that they are everywhere. According to them, one machine drives another machine, while machines are also being driven by machines. And what is more important is the fact that every machine is coupled and connected to another machine (Deleuze \& Guattari, 1984, p. 1). For example, the breast is a machine that produces milk, while the mouth is a machine that is coupled to it. There is, however, more to the workings of machines. Their networks can be defined in terms of interruptions or breaks (coupures), which means that every machine is related to a flow and 'every machine functions as a break in the flow in relation to the machine to which it is connected, but at the same time it is also a flow itself, or the production of a flow, in relation to the machine connected to it' (Deleuze \& Guattari, 1984, p. 36). For the performer/instrument relation, this means that the voice can be theorized as a machine. The performer is a machine and the instrument is a machine, and all are connected through flows and breaks in the flow. 'Everywhere there are breaks-flows', Deleuze and Guattari (1984, p. 37) suggest. Indeed, the breaking down of the machine constitutes an integral part of the machine's functioning. It is the interruption that 'conditions this continuity: it presupposes or defines what it cuts into as an ideal continuity' (Deleuze \& Guattari, 1984 , p. 36). Just as the mouth cuts off the milk or the flow of air, the penis interrupts the flow of urine as well as the flow of sperm, we are told (Deleuze \& Guattari, 1984, p. 36). 
I believe that this 'machinic' view becomes essential in approaching the work 'IKAS'. What happens if one thinks of the voice as cutting into the instrumental space rather than as shaping itself in harmonious accordance with the instrumental prosthesis? This occurs in a similar way with the mouth and breast machines: the mouth not only sucks the milk of the breast, but it also cuts off the milk from the breast. What if the voice is thought of as interfering with or distorting the instrument? When the voice cuts into the instrument it distorts not only the flow of air that produces a sound, but it also cuts into the flow of one's voicing oneself. The voice that gives rise to one's being, to the voicing of oneself, cuts back at the performer and also turns back upon itself as some kind of feedback. This sort of interference of the voice into the instrument can be found throughout the entire work of 'IKAS'.

For example, the performer is asked to voice the consonants of ' $\mathrm{t}$ ' and ' $\mathrm{z}$ ' in combination with an (any) instrumental sound (Figure 1). Looking at this more closely, it seems an almost impossible endeavor since those consonants affect a rather harsh closure of the throat, hindering the air from traveling through to the instrument. It becomes physically impossible and conceptually startling to produce an instrumental sound with those consonants. The consonants ' $t$ ' and ' $z$ ' interfere with the shaping of one's vocal cavity. How is one meant to play this? A similar gesture occurs just before the ' $t / z$ ' consonant gesture. A ' $w$ ' (with a ' $u$ ' added in brackets underneath) is supposed to be produced in combination with an instrumental sound. Similarly, the consonant ' $w$ ' restricts the airflow in the throat, making it hard for air to pass through (Figure 1).

I refer to these gestures as 'consonant interferences' of the instrumental sound in 'IKAS' machinic workings. They constitute one type of fragment in the work. Another fragment that effects breaks in the workings of the performer-voiceinstrument-machine occurs when a stable sound, such as the sustained multiphonic sound (in itself already a rather unstable sound in terms of air column vibration!), becomes interrupted by a 'Flutterzunge' (a flutter of the tongue) that somehow seems to cut into the sonic stability of the multiphonic (Figure 2).

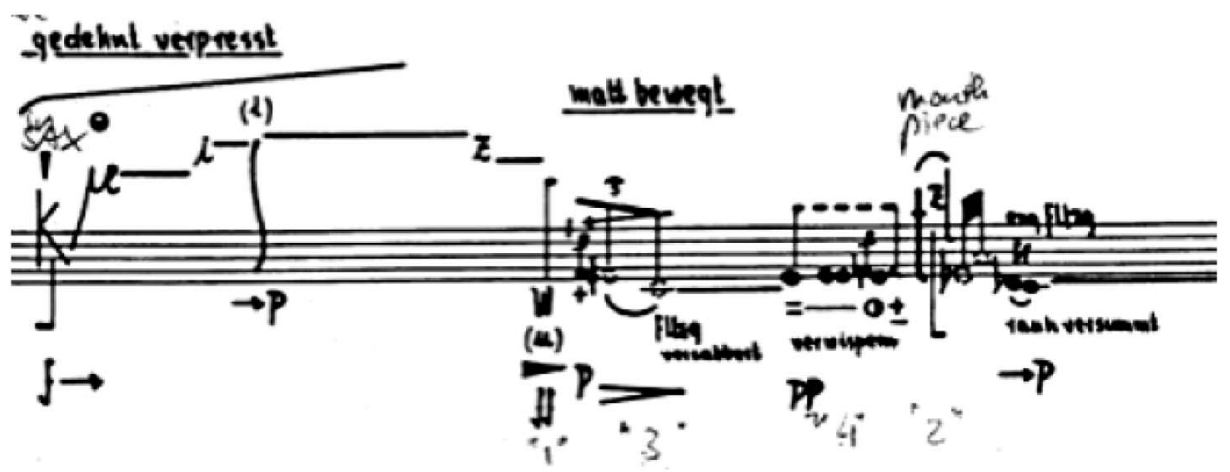

Figure 1 Extract from 'IKAS', line 3. 
Consider also the high ' $\mathrm{f}$ in Figure 2: it is held quietly, while at the same time it becomes 'disturbed' by the consonants ' $w$ ' and 'ws'. Like the above gestures, these ' $w$ ' or 'ws' gestures are far from physically possible. The added marking of 'locker' (light or loose) seems to deepen this paradox (Figure 2). In a similar way of cutting off sustained elements, Hespos indicates to cut off a sustained ' $e$ ' by the consonants ' $t / k$ ' (Figure 3). This interruption is then followed by a series of vowels. Note that this is the first and only time in the work that vowels are used! The series of vowels constitutes a kind of primordial, a violent, breathless ('atemlos'), loud scream ('fff' is the marking!). Hespos marks 'fürchterlich' (horrible or fearsome) and 'mit starrer Kehle' (with rigid throat).

This in itself makes for another paradox, since for the first and only time in the work in which vowels are used the performer is not asked to open up, to be free and loose, but rather is asked to close off his or her throat. At the only moment where the performer would physically be able to open their throat (' $u$ ' and 'a' are generally

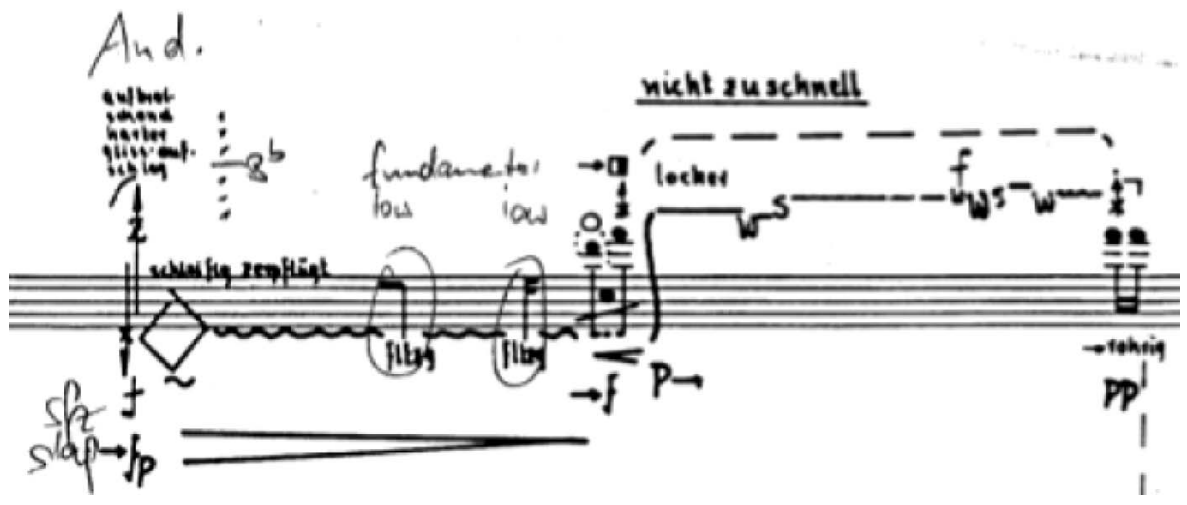

Figure 2 Extract from 'IKAS', line 3.

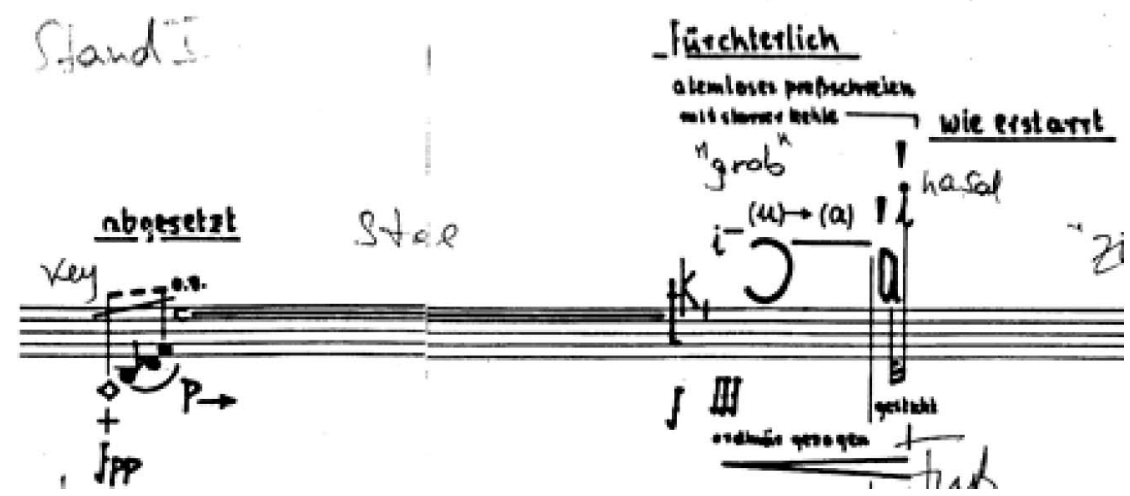

Figure 3 Extract from 'IKAS', line 3. 
produced with an open throat), at a moment where she would be able to let the sound come out freely, she is asked to voice herself as rigid and tense. This scream constitutes the climax of the work, even if it is rigid and tense.

A third type of fragment in 'IKAS' is the performance of vocal sounds away from the instrument. Whereas the other two fragments (the consonants that interfere with the shaping of the vocal apparatus and the consonants that are employed to cut off musical gestures) are used in combination with the instrument, the third fragment consists of sounds to be made away from the instrument. One sees this exemplified in the previously mentioned climactic primordial scream and also in Figure 4, in which the consonants of ' $t$ ', ' $p$ ' and ' $z$ ' are produced away from the instrument.

Without going into a more detailed analysis of the work, what can be said is that the work is of slight schizophrenic nature. Throughout the performance of 'IKAS' both performer and listener are constantly 'on edge': musical fragments are never maintained, sustained notes always become interrupted or interfered into. A Deleuzeian reading exposes such interruptions not as negative, however, but as something productive: 'the breaks in the process are productive, and are reassemblies in and of themselves. Disjunctions, by the very fact that they are disjunctive, are inclusive' (Deleuze \& Guattari, 1984, p. 42). Indeed, interruptions are not to be understood as the opposite of continuity; interruptions condition continuity, as pointed to above. For approaching a work such as 'IKAS', it implies that rather than thinking of the voice-machine as extending into the instrument-machine, one needs to think of the voice-machine as cutting off the instrument-machine, just as Deleuze tells us that the anus cuts off the flow of shit.

For the performer, this entails that, rather than thinking of the air as coming from the diaphragm, proceeding to the lungs, then to the vocal cavity, he or she needs to consider the threshold that marks the space between the mouth/lips and the saxophone reed. The performer needs to think how the sound of a ' $w$ ' can make a sound with the instrument, rather than thinking of the ' $w$ ' as the sound that comes

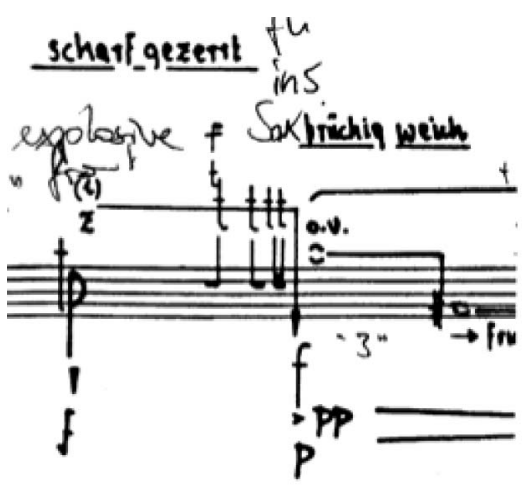

Figure 4 Extract from 'IKAS', end of line 3. 
from inside and goes through the instrument. This space, the 'in-between', then, becomes of major concern. It is this space, gap or junction between the machines, the part where the machines connect, to which the performer's focus should be directed. In fact, it is this space where the breaks most commonly occur, or where at least they become visualizable. It is here, at the intersection of the two machines, when the mouth cuts off the milk, that one 'sees' the milk dripping out of the mouth machine. I think that these 'interruptions' in Hespos' work imply a variety of things, in particular if bearing in mind the word's etymology not only as 'to break' or 'to break into', but also as to 'gape apart' (Chambers, 1960): 'IKAS', then, not only widens expectations, it also stretches notes, as well as the physically possible. And further, the work constantly pushes to the limit the performer's abilities, in particular with view to his or her physical and conceptual engagement with the work. In this way, 'IKAS' can be seen to widen the performer's understanding of her body, her instrument, as well as their respective connections or disconnections.

\section{A Paradoxical Resting Closure}

Right at the end of the work, the cutting off of the flows seems to come to a rest (Figure 5). The machines wind down, as the trill starting from very quiet ('pp') diminuendo-ing into even less, into nothing, suggests. The marking reads 'rauschig verblasen'. A rather un-Hespos-ian gesture? No interruption, just a pure fade-out to silence?

It is not quite that simple, however. One must only examine the indicated markings more closely to discover another of Hespos' paradoxes; a tongue-in-cheek gesture maybe? The marking 'verblasen' uses the German prefix 'ver-', indicating 'mis' or 'wrong', as in the words 'ver-kehrt' ('wrong'), 'ver-ändert' ('changed') or 'ver-kommen' ('degenerated'). In 'verblasen', the idea of 'mis-blowing' is implied-something most performers are not accustomed to doing, or often do not know how to do. Even in an apparent resting moment, in which the sound for once seems to fade away uninterruptedly, the notion of mis-, of interruption, of interference, is implied.

'IKAS', then, is a schizoid work par excellence; a work that continuously reminds one of the schizophrenic at work, in particular of the voice as disturbance in itself.

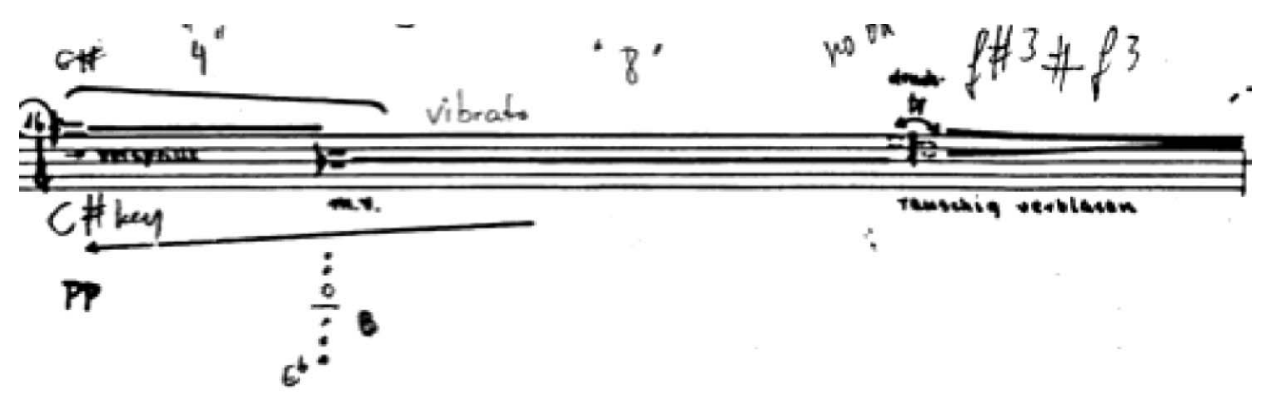

Figure 5 Extract from 'IKAS', 'Resting Closure'. 
The performer is made to see the voice not simply as an 'emission of the body', but, as Connor suggests, as a 'straining of air'. The voice is a 'striving, and a disturbance', one that 'subjects the world to strain' (Connor, 2005). Thus, to me 'IKAS' is a work that 'brings about transverse communication, transfinite summarization, polyvocal and transcursive inscriptions on its own surface, on which the functional breaks of partial objects are continually intersected by breaks in the signifying chain, and by breaks effected by a subject that uses them as reference points in order to locate itself (Deleuze \& Guattari, 1984, p. 43). 'IKAS' exposes the breaks in the workings of the performer-voice-instrument machine, and by laying bare those workings, demands a re-orientation on the part of the performer towards searching for conceptual ways of playing that may not be readily at hand.

\section{Notes}

[1] Already Marshall McLuhan (1964) saw the voice as one of the principal 'extensions' of man.

[2] Etymonline: www.etymonline.com (accessed November 2005).

[3] A project that deals with instrumental prosthesis in music is the work 'Music for Prosthetic Conga' by Pedro Rebelo: www.sarc.qub.ac.uk/ prebelo/index/works/prostheticcongas/ left.htm (accessed November 2005).

[4] www.stelarc.va.com.au (accessed November 2005).

[5] www.stelarc.va.com.au (accessed November 2005).

[6] I have questioned the formula 'from-to', the idea of the instrument as extension, in Schroeder (2005).

[7] Score: Hans-Joachim Hespos (1982), 'IKAS—ein entrée für altsaxophon'. Hespos Edition, Delmenhorst, H 028 E. All score extracts are represented with the permission of the composer.

\section{References}

Chambers (1960). Twentieth century dictionary (W. Geddie, Ed.). London: W \& R Chambers Ltd. Connor, S. (2000). Dumbstruck: A cultural history of ventriloquism. Oxford: Oxford University Press. Connor, S. (2005). The strains of the voice. English text of an essay written to accompany the exhibition 'Phonorama: Eine Kulturgeschichte der Stimme als Medium', curated by Brigitte Felderer, at the Zentrum für Kunst und Medientechnologie, Karlsruhe, 18 September 2004-30 January 2005. Available online at: www.bbk.ac.uk/english/skc/strains (accessed November 2005).

Cumming, N. (2000). The sonic self: Musical subjectivity and signification. Bloomington, IN: Indiana University Press.

Deleuze, G. \& Guattari, F. (1984). Anti-Oedipus: Capitalism and schizophrenia. London: Athlone Press.

Leroi-Gourhan, A. (1993). Gesture and speech (A. Bostock Berger, Trans.). Cambridge, MA: MIT Press.

MacLuhan, M. (1964). Understanding media: The extensions of man. London: Routledge \& Kegan Paul.

Merleau-Ponty, M. (1999). Phenomenology of perception (C. Smith, Trans.). London: Routledge.

Schroeder, F. (2005). The touching of the touch: Performance as itching and scratching a quasi-incestuous object. Extensions Journal: The Online Journal of Embodied Technology. Available online at: www.wac.ucla.edu/extensionsjournal/v2/index2.htm (accessed November 2005). 